Skinner, F. A. (1960). J. gen. Microbiol. 22, 539-554

\title{
The Isolation of Anaerobic Cellulose-decomposing Bacteria from Soil
}

\author{
BY F. A. SKINNER \\ Soil Microbiology Department, Rothamsted Experimental Station, \\ Harpenden, Hertfordshire
}

\begin{abstract}
SUMMARY: A strictly anaerobic mesophilic species of cellulose-decomposing bacteria was isolated from soil by a new technique. Cultures were made in screwcapped bottles with media containing finely divided cellulose. The method and apparatus used for filling these bottles with reduced media and nitrogen is described. Flocculation of cellulose particles in agar media was prevented by incorporating a low concentration of sodium carboxymethyl cellulose. Cellulolytic colonies in cellulose agar media were of two types, punctiform and spreading. The isolate derived from a punctiform colony digested cellulose with the formation of formic, acetic and malic acids, carbon dioxide and hydrogen. Essential growth factors were provided by yeast and soil extracts. Surface colonies on yeast peptone cellobiose agar were differentiated into convex entire central zones and thin transparent irregular margins. In deep culture with the same medium the isolate grew either as discrete lenticular colonies or spread rapidly throughout the agar. These growth forms were unstable, the type appearing in any one culture being unpredictable. In many respects the isolate resembles Clostridium cellobioparum Hungate, and is probably a strain of this species. It differs from C. cellobioparum, however, in producing little or no cellobiose but abundant glucose from cellulose in liquid culture.
\end{abstract}

Early work on the anaerobic decomposition of plant residues suggested that some micro-organisms could convert cellulose directly to methane but later investigations have shown that two groups of strictly anaerobic bacteria are concerned in this process: the cellulose-decomposers which form intermediate products of low molecular weight, and the methane-producers which use these intermediates as substrates (Barker, 1956). Our knowledge of the whole process is still not extensive, mainly because the organisms of both groups have proved difficult to isolate and study in pure culture. It seems clear from the literature, reviewed in detail by Hungate (1950), that several workers have obtained pure cultures of mesophilic cellulolytic anaerobes from human faeces (Khouvine, 1923), soil and other materials (Clausen, 1931), horse faeces (Cowles \& Rettger, 1931) and cattle rumen (Hungate, 1944). All these isolates were rod-shaped organisms with terminal spores and referable to the genus Clostridium. The existence of non-spore-forming species in rumen, soil and sewage sludge was also demonstrated by Hungate $(1947,1950)$ who used methods designed to isolate cellulolytic bacteria directly from natural sources without first making enrichment cultures because enrichment seems to favour the development of spore-forming types at the expense of non-spore-forming types.

The object of this work was to study some species of mesophilic anaerobic cellulolytic bacteria, particularly those likely to be common in soils and 
composts or able to ferment highly cellulosic plant residues rapidly. Enrichment cultures were used, despite the objection to them noted above, because the prevalence of spore-forming bacteria in naturally fermenting materials suggested that they might be of greater importance in these habitats than non-spore-formers which predominate in more specialized environments such as the rumen.

\section{METHODS}

Preparation of finely divided cellulose. Fifteen g. Whatman ashless cellulose powder (Standard grade) and $80 \mathrm{ml}$. distilled water were treated in a macerator (MSE) for $20 \mathrm{~min}$. The resulting slurry was divided into several portions and each shaken with $250 \mathrm{ml}$. distilled water in a measuring cylinder. After settling, the turbid supernatant fluids were collected by siphoning and each residue treated as before with another $250 \mathrm{ml}$. water. This process was continued until supernatant fluids were only slightly turbid. Bulked fluid was then made acid with a few drops of $\mathrm{N}-\mathrm{HCl}$ and allowed to stand overnight. The flocculated cellulose $(c .300 \mathrm{ml}$.) was concentrated and washed by centrifugation with several changes of distilled water until the deflocculation point, as indicated by the appearance of slightly turbid centrifugate, was reached. The cellulose was then re-suspended in distilled water, made up to $2 \%(w / v)$, and stored in the refrigerator until required. Three batches made at different times gave yields of fine cellulose of $23 \cdot 3,22 \cdot 7$ and $23 \cdot 2 \%$ of the original $15 \mathrm{~g}$. used. Higher yields could not be obtained because the fine material seems to derive from the broken ends of the original fibres. When these ends become polished the macerator has almost no further action. The yield of fine cellulose could be increased up to $c .50 \%$ by applying the above method to short fibres prepared by soaking absorbent cotton wool in near-concentrated $\mathrm{HCl}$ (Hungate, 1950).

Almost all the cellulose-containing media used were made up with cellulose prepared as described. Only large liquid cultures (for analysis of fermentation products) were made with cellulose prepared by ball-milling (Hungate, 1950) because a suitable mill only became available at a late stage in the work.

Buffered mineral salt solution for preparation of cellulose media. This contained $\left(\mathrm{NH}_{4}\right)_{2} \mathrm{SO}_{4}, 1 \cdot 0 \mathrm{~g}$.; $\mathrm{K}_{2} \mathrm{HPO}_{4}, 13 \cdot 0 \mathrm{~g}$; $\mathrm{KH}_{2} \mathrm{PO}_{4}, 7 \cdot 0 \mathrm{~g}$.; $\mathrm{CaCl}_{2}, 0 \cdot 1 \mathrm{~g}$.; $\mathrm{MgSO}_{4} \cdot 7 \mathrm{H}_{2} \mathrm{O}, 0 \cdot 1 \mathrm{~g}$; $\mathrm{NaCl}, 2 \cdot 0 \mathrm{~g}$.; distilled water, 1.0 l.; $\mathrm{pH} 7 \cdot 0$.

Liquid cellulose medium $A$. Buffered mineral salt solution, $50.0 \mathrm{ml}$; resazurin solution $(0 \cdot 1 \%, \mathrm{w} / \mathrm{v}), 0 \cdot 1 \mathrm{ml}$; soil extract (Fred \& Waksman, 1928), $15 \mathrm{ml}$; ; yeast extract (Difco), 0.01 g.; cellulose suspension (2\%, w/v), $20 \mathrm{ml}$; cysteine hydrochloride, $0.01 \mathrm{~g}$.; distilled water to $100 \mathrm{ml}$.

Liquid cellulose medium $B$. Buffered mineral salt solution, $50.0 \mathrm{ml}$; resazurin solution $(0 \cdot 1 \%, \mathrm{w} / \mathrm{v}), 0 \cdot 1 \mathrm{ml}$; y yeast extract (Difco), $0 \cdot 1 \mathrm{~g} . ;$ cellulose suspension $(2 \%, \mathrm{w} / \mathrm{v}), 20 \mathrm{ml}$; ; cysteine hydrochloride, 0.05 ; distilled water to $100 \mathrm{ml}$.

Addition of sodium carboxymethylcellulose (CMC) to cellulose media. CMC $(0.5 \mathrm{~g}$.) was added slowly to $50 \mathrm{ml}$. of mechanically stirred buffered mineral salt solution. Complete solution was effected by stirring the mixture for 
15 min. after all the $\mathrm{CMC}$ had been added. A suitable volume was added to cellulose agar medium to give the required $\mathrm{CMC}$ concentration.

Enrichment culture medium. This contained: $\left(\mathrm{NH}_{4}\right)_{2} \mathrm{SO}_{4}, \mathrm{I} \cdot 0 \mathrm{~g} . ; \mathrm{K}_{2} \mathrm{HPO}_{4}$, 1.0 g.; $\mathrm{MgSO}_{4} .7 \mathrm{H}_{2} \mathrm{O}, 0.5 \mathrm{~g}$.; $\mathrm{CaCO}_{3}, 2 \cdot 0 \mathrm{~g}$.; $\mathrm{NaCl}$, trace; distilled water, 1.01 . (Omelianski, 1902).

Nutrient agar. Peptone, 10 g.; Lab-Lemco, 3.0 g.; yeast extract, $1 \cdot 0$ g.; $\mathrm{NaCl}, 5 \cdot 0$ g.; Bacto-agar, 15.0 g.; distilled water, 1.0 l.; $\mathrm{pH}$ adjusted to 7·0-7.2.

Yeast-peptone agar. Yeast extract (Difco), 15.0 g.; peptone, 5.0 g.; Bacto-

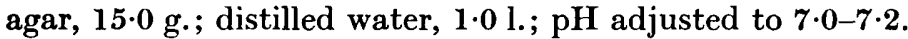

Incubation. All cultures were incubated at $35^{\circ}$.

\section{RESULTS}

\section{Enrichment cultures}

Eight $4 \mathrm{oz}$. reagent bottles each containing $c .2 \cdot 0 \mathrm{~g}$. chopped filter paper and $100 \mathrm{ml}$. enrichment culture medium were plugged with cotton wool and autoclaved at $15 \mathrm{lb}$./sq.in. for $15 \mathrm{~min}$.; the final $\mathrm{pH}$ value was $\mathbf{7 \cdot 1}$. Each sterile bottle was inoculated with $c .1 \cdot 0 \mathrm{~g}$. soil or other material and after mixing was filled to the top with sterile solution, fitted with a flamed glass stopper and incubated. Cultures were prepared with inocula of three local soils, two kinds of compost, byre litter, river mud and sewage sludge.

After 7 days, some small clear patches had appeared on the paper in the culture inoculated with soil from a Rothamsted field (Broadbalk, plot 8), and gas containing some $\mathrm{H}_{2} \mathrm{~S}$ was being freely evolved. Four days later this culture had a sour odour, gas production had ceased and the $\mathrm{pH}$ value had fallen to 5.5. Calcium carbonate was then added until the $\mathrm{pH}$ was $6 \cdot 2$ and incubation continued. After 38 days obvious digestion of the paper was in progress, gas again being evolved. All recognizable traces of paper had disappeared by the

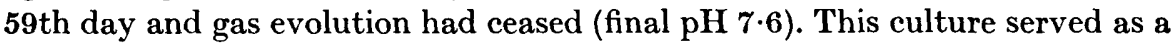
source of inocula for subsequent work.

In two other cultures (compost and soil) cellulose was digested appreciably only between the 38th and 59th days; in the remaining five cultures, cellulose was scarcely attacked. None of these cultures developed a sour odour or a $\mathbf{p H}$ value lower than $6 \cdot 0$.

\section{Experimental work on isolation procedures}

At first an attempt was made to secure colonies of the cellulose-decomposer in cellulose agar by using the method of Hungate (1950) which was devised to prevent such oxygen-sensitive organisms being subjected to oxidizing conditions during inoculation and the early stages of incubation. Essentially this method consists of the preparation of a small batch of reduced medium which, after sterilization, is distributed aseptically by a pipette containing oxygenfree gas $\left(\mathrm{CO}_{2}\right.$ or nitrogen) into sterile tubes. Each tube is then inoculated, flushed with sterile $\mathrm{O}_{2}$-free gas, stoppered, and allowed to cool so that the medium forms a slope or film. This method has yielded results which have increased our knowledge of the cellulose-decomposing anaerobes considerably, 
but attempts to use it in this laboratory with a phosphate-buffered medium not containing rumen fluid met with little success. Usually the medium became oxidized during transfer to the culture tubes and remained so during incubation. Oxidized medium (pink because some completely reduced resazurin had become oxidized to resorufin) has never been found to support growth of cellulolytic anaerobes. The medium in some inoculated tubes eventually became reduced to the colourless condition; these yielded only a few haloed colonies after several weeks.

Better results were obtained by using as culture vessels screw-capped bottles which could be autoclaved after filling rapidly with unsterile reduced medium and a gas phase of oxygen-free nitrogen. One oz. culture bottles were used for liquid media (15 ml./bottle) and $3 \mathrm{oz}$. flat-sided bottles for agar media (8-10 ml./bottle). The following method was used to make subcultures into liquid medium. One hundred ml. medium A (Methods) without the reducing agent were prepared in a flask fitted with a rubber stopper carrying an inlet tube extending to the bottom of the vessel and a hole for the escape of gases. After boiling for $5 \mathrm{~min}$. with a current of oxygen-free nitrogen passing through the medium, $0.04 \mathrm{~g}$. cysteine hydrochloride was added and boiling continued for another minute. The stream of nitrogen was passed until the medium had cooled to room temperature and subsequently while the culture bottles were being filled by pipette. Filled bottles were flushed with nitrogen, fitted with tightly screwed caps and autoclaved at $15 \mathrm{lb} . / \mathrm{sq} . \mathrm{in}$. for $15 \mathrm{~min}$. When cool, each bottle was inoculated with pieces of partially digested filter paper from the primary enrichment culture, flushed with sterile nitrogen and capped. By the 10th day, cellulose was undergoing rapid digestion, the supernatant fluid was turbid and gas was being evolved. After 16 days there remained only a thin sediment of cellulose particles and bacteria. Long rod-shaped organisms, many with terminal spores, and small masses of cocci were present. Other subcultures were made in the same way during development of the improved method of medium preparation described below.

Preparation and distribution of media. Although the preparation of individual anaerobic cultures had been made simpler and more efficient by the use of screw-capped bottles which could be sterilized after filling, difficulties were still encountered with the gas-filled pipette used for transferring medium from the reservoir in which it had been made. Usually it was impossible to transfer medium in this way without it acquiring a pink colour indicative of oxidation. This colour almost always faded during autoclaving but frequently reappeared on subsequent cooling. The apparatus depicted (Fig. 1) allowed bottles to be filled without oxidation of the medium. The apparatus is used as follows.

One hundred ml. medium without reducing agent are added to the Pyrex flask (marked at $100 \mathrm{ml}$.) and the stopper, less sliding delivery tube (7) fitted. The medium is then boiled gently for $5 \mathrm{~min}$., oxygen-free nitrogen (c. $100 \mathrm{ml}$.) min.) being bubbled through it at the same time via the inlet tube. When the medium is rich in reducing substances (e.g. contains a high concentration of yeast extract), the resazurin is quickly reduced to pink resorufin, otherwise 
the original bluish purple colour persists. The flask is then allowed to cool to room temperature with the sliding delivery tube in place in the guide tube (6), the flow of nitrogen continuing. When cold, the sliding tube is removed, gas flow stopped and the reducing agent (e.g. cysteine $\mathrm{HCl}$ ), dissolved in a little water, pipetted through the guide tube. At this stage the medium can, when necessary, be made up to volume with boiled water. The sliding tube is then replaced and gas flow resumed at a higher rate $(500-750 \mathrm{ml} / \mathrm{min}$.).

A screw-capped bottle marked at about the required volume is flushed with nitrogen by holding it under the end of the sliding tube as shown. After a few seconds, the flask is agitated gently to ensure even dispersion of the

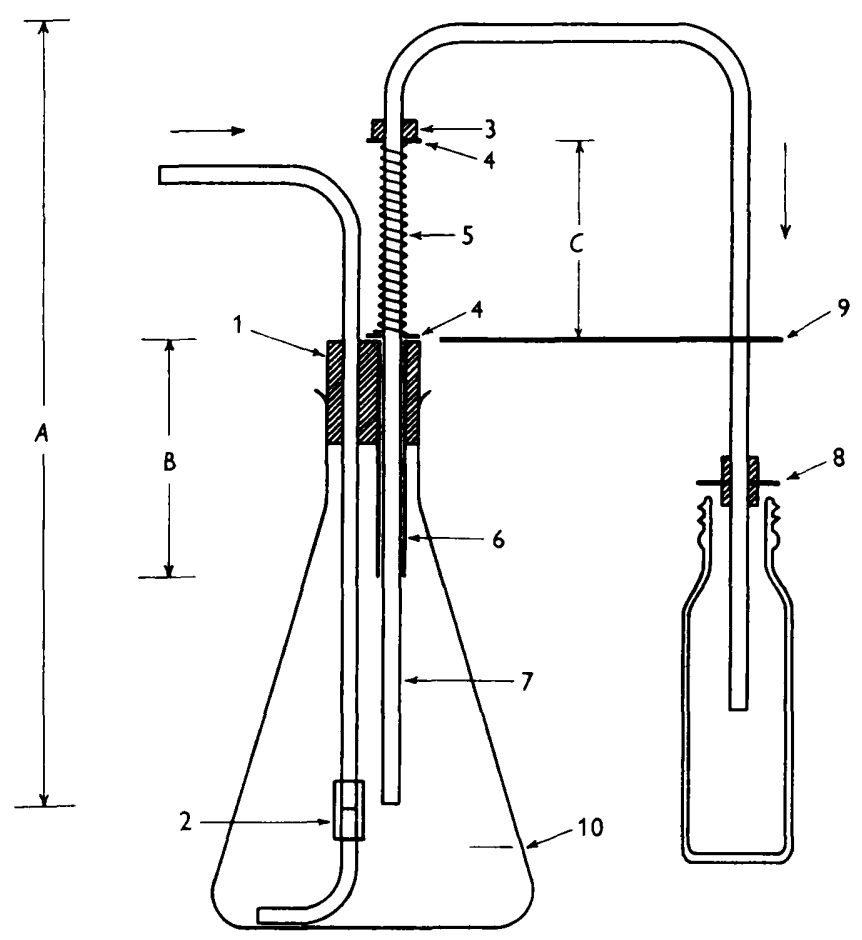

Fig. 1. Apparatus for preparation and distribution of reduced media.

Fig. 1. 1, Rubber stopper; 2, 'Tenatube' joint on inlet tube; 3, rubber ring; 4, stainless steel washers reamed to fit glass tube; 5 , stainless compression spring, 0.25 in. internal diam., 10 turns/in.; 6, glass guide tube, $5.5 \mathrm{~mm}$. internal diam.; $\boldsymbol{\gamma}$, sliding delivery tube, $5 \mathrm{~mm}$. external diam.; 8, sheet rubber washer, $1 \mathrm{~mm}$. thick; 9, narrow loop of $14 \mathrm{s.w.g}$. galvanized iron wire enclosing downward limb of sliding tube and fixed into top of rubber stopper (attachment not shown), this prevents the sliding tube from swinging in the guide tube; 10, graduation mark. Dimensions : $(250 \mathrm{ml}$. flask for preparing up to $100 \mathrm{ml}$. medium); A, $190 \mathrm{~mm}$; B, $65 \mathrm{~mm}$; C, $45 \mathrm{~mm}$. (1 l. flask for preparing 100 $500 \mathrm{ml}$. medium.); A, $300 \mathrm{~mm}$.; B, $100 \mathrm{~mm}$.; C, $70 \mathrm{~mm}$.

cellulose particles and the sliding tube depressed until its lower end is below the medium, whereupon the latter passes over into the flushed bottle. When sufficient medium has transferred, the delivery tube is allowed to rise, by 
means of the compression spring (5), out of the medium and gas passes over to flush the bottle finally before the cap is quickly screwed on.

To support the apparatus while allowing some freedom of movement for occasional shaking, a spring clamp is used. This consists of a Terry clip, to grip the flask neck, fixed to one end of a $15 \mathrm{~cm}$. length of suitable tension spring the free end of which is held in a clamp boss. This apparatus permits the filling of culture bottles with deoxygenated medium which, during autoclaving, becomes fully reduced to the colourless condition. Moreover, at room temperature the gas phase is at atmospheric pressure so that when caps are removed for inoculation there is no inrush of air to oxidize and possibly to contaminate the medium. A slight modification to the method is advisable when flat bottles are being filled with hot agar medium. When cold each bottle is unsealed and flushed with a fast flow of nitrogen to restore atmospheric pressure. Bottles are then capped and sterilized as above.

After inoculation, each bottle is flushed with sterile oxygen-free gas through a sharply bent pipette (Hungate, 1950) before the cap is replaced. Alternatively, inoculation may be made by hypodermic needle directly through the cap liner. In this way the inoculum does not come into contact even momentarily with oxygen.

Traces of air sometimes leak into bottles during the lengthy incubation period, with consequent oxidation of the medium. This effect, which has caused only occasional trouble with liquid cultures, is less likely to occur when $20 \mathrm{ml}$. medium are used instead of the $15 \mathrm{ml}$. used in the early experiments. When leakage does occur, a culture can usually be saved by partially evacuating the bottle with a hypodermic needle passed through the rubber cap liner and connected to a vacuum line. The black rubber liners normally supplied with the bottles or white rubber liners (TCV quality, Esco Rubber Ltd.) are suitable, and metal caps with 3/16 in. diam. holes are to be preferred. Large screw-capped culture vessels are conveniently filled individually (see Qualitative analysis of fermentation products).

Subcultures in solid media. A solid medium for use in 3 oz. screw-capped medical flat bottles was prepared. This differed from the liquid medium $\mathbf{A}$ in that each $100 \mathrm{ml}$. medium contained $30 \mathrm{ml}$. of a $2 \%(\mathrm{w} / \mathrm{v})$ suspension of cellulose and $1.5 \mathrm{~g}$. Bacto agar. After inoculation and flushing with $\mathrm{O}_{2}$-free nitrogen, each capped bottle was placed so that the medium set as a shallow layer on one of the larger sides and then incubated horizontally with the agar side uppermost. Vertical incubation was unsatisfactory because cellulolytic bacteria accumulated in the condensate and caused progressive upward digestion of the cellulose which obscured digestion by individual colonies. Bacterial colonies, surrounded by clear haloes where cellulose particles had been digested, grew in and on the medium. Microscopic examination of these colonies was easier than in the test tubes earlier used as culture vessels.

Prevention of flocculation of cellulose particles in agar media. These bacteria, however, grew very slowly; 2 to 3 weeks of incubation being necessary before haloed colonies appeared. Moreover, the fine cellulose particles flocculated readily in the presence of electrolyte constituents of the medium. It was 
thought that slow growth might be partly explained by inability of the bacteria to come into contact with these flocculated and therefore unevenly distributed particles of cellulose, and that growth might be stimulated by adding a soluble cellulose derivative which would be available to any cellulose bacterium able to use it. Evidence from investigations on fungi (Siu, 1951) indicates that a cellulose derivative can be readily used provided that the degree of substitution is less than unity (i.e. mean value of less than $1 \cdot 0$ substituent group/anhydroglucose unit). Sodium carboxymethylcellulose (CMC) was selected as a possibly useful supplement to cellulose agar media.

Two batches of cellulose agar were prepared; one without any addition, the other supplemented by $0.5 \%(\mathrm{w} / \mathrm{v})$ sodium CMC with a degree of substitution of 0.45-0.55 (Edifas B; I.C.I.). Flat bottles of these media were prepared as described above, and each inoculated with a loopful of a shaken liquid culture. Cellulolytic bacteria had grown in the cultures without CMC by the 43rd day, but none developed in those containing CMC during a total incubation period of 106 days. Thus this CMC seemed to inhibit rather than stimulate growth of the cellulolytic bacteria. The fact that very few colonies of any type grew in the CMC cultures suggested that the inhibitor was non-specific. However, excellent dispersion of cellulose particles occurred in the CMC medium, whereas cellulose flocculated as before in the medium without CMC. It was considered that the use of other grades of CMC, possibly at lower concentrations, would have the same beneficial effect on dispersion of the cellulose particles but would also be non-inhibitory. Cultures were made with cellulose agar containing $0.5 \%(\mathrm{w} / \mathrm{v})$ sodium CMC of the grade CMC 70-Low (Hercules Powder Co. Inc.) having a degree of substitution range of $0 \cdot 65-0 \cdot 85$. This compound did not inhibit growth of the cellulolytic bacteria and was more efficient than Edifas B in suspending the cellulose particles. An experiment made to determine the effect of CMC 70-Low on cellulose particles in mineral salt solution showed that it acted as a satisfactory suspending agent for the particles at a concentration as low as $0.01 \%(w / v)$; though in agar media sterilized by autoclaving the lowest effective concentration was $0.05 \%(w / v)$. At this concentration the CMC 70-Low has negligible effect on the viscosity (manufacturer's data), so it presumably acted as a protective lyophilic colloid for the cellulose particles. Agar media containing dispersed finely divided cellulose are superior to those with flocculated cellulose, even though the rate of growth of cellulolytic bacteria is not increased. The main advantage is that haloes surrounding colonies are more sharply defined and contain few if any residual particles of undigested cellulose; thus, they can be searched more effectively with a low-power microscope for small colonies of contaminants. Such cultures are also more reproducible.

Types of cellulolytic colonies. In a series of cellulose agar cultures of the type described, thin iridescent surface colonies had appeared by the 14th day, though digestion of the surrounding cellulose was not very marked until the 22nd day. After 25 days, large numbers of white punctiform colonies, each encircled by a clear digestion zone, had also appeared. Colonies of both types which seemed free from contaminating colonies were transferred by Pasteur 
pipette to bottles of liquid cellulose medium A. Two of these liquid cultures, one derived from a spreading, and the other from a punctiform colony, provided inocula for further cultures in cellulose agar. Both types of colony appeared in all these agar cultures.

\section{Isolation of a cellulolytic anaerobe}

One punctiform colony in a cellulose agar culture (Pl. 1, fig. 1) was transferred by fine pipette to a $5 \mathrm{ml}$. screw-capped bottle containing $2 \mathrm{ml}$. sterile saline $(\mathrm{NaCl}, 0.75 \%, \mathrm{w} / \mathrm{v})$ and $1 \mathrm{~g}$. sand, which was then shaken rapidly (Microid shaker) for $5 \mathrm{~min}$. This treatment did not break up the colony entirely but only reduced its size. This suspension was used to inoculate ten bottles of liquid cellulose medium B. Other liquid cultures were made in the same way from other colonies. In all, 31 cultures were made and during an incubation period of 49 days digestion of cellulose took place in all but three of these cultures. After 33 days, the cultures were tested for the presence of contaminants by incubating inocula from them on plates of yeast peptone agar (Methods). Duplicate plates were made from each bottle; one was incubated aerobically, the other anaerobically in a McIntosh \& Fildes jar (atmosphere of hydrogen, $\left.90 \%, \mathrm{v} / \mathrm{v},+\mathrm{CO}_{2}, 10 \%, \mathrm{v} / \mathrm{v}\right)$.

After 2 days, all aerobic plates except four carried a good growth of a spore-forming contaminant. Positive plates were discarded and the four negative plates incubated until they finally dried out; no colonies appeared. Of the anaerobic plates, 10 showed no growth after 2 days; incubation of these was continued. After a further 6 days, one anaerobic plate still showed no growth but five (including four derived from cultures which had no aerobic contaminants) displayed microscopic colonies in vast numbers along the inoculation streaks. The bacteria were long rods with spherical terminal spores similar to those seen in close association with cellulose in liquid cultures.

After subculture on yeast peptone agar, selected microscopic colonies were streaked on to plates of yeast peptone agar containing $0 \cdot 1 \%(\mathrm{w} / \mathrm{v})$ cellobiose which was added to the molten medium in each plate as an aliquot of aqueous solution $(1.5 \%, w / v)$ sterilized by filtration. After 4 days of anaerobic incubation small colonies were growing on all plates. Selected colonies were again subcultured on yeast peptone cellobiose agar and the new colonies $(0 \cdot 1-$ $1.0 \mathrm{~mm}$. diam.) after 5 days ( $\mathrm{Pl}$. 1, fig. 3) picked off into bottles of liquid cellulose medium. Satisfactory digestion of cellulose took place in all cultures.

Cellulose agar cultures were also prepared; in some the inoculum was added to the molten medium and in others the inoculum was streaked on the surface of the solidified medium. Digestion of cellulose occurred in six out of nine streak cultures. Growth in these streak cultures was of the thin iridescent spreading type noticed earlier with impure cultures, though the isolate had originated from a punctiform colony. 


\section{Characters of the isolate}

Cells of this organism are slender, often slightly curved, Gram-negative rods, $0 \cdot 3-0.7 \mu \times 2-8 \mu$, with terminal spherical spores $c$. $1 \mu$ diam. and peritrichous flagella. The isolate is a strict anaerobe, though it can tolerate exposure to oxygen during transfer from one culture to another. Preliminary studies have indicated that an $E_{h}$ value of about $-100 \mathrm{mV}$. is necessary before growth can begin in liquid cellulose medium.

Cultural characteristics. Cultures referred to below were incubated anaerobically in McIntosh \& Fildes jars with an atmosphere of hydrogen $(90 \%, \mathrm{v} / \mathrm{v})$ and $\mathrm{CO}_{2}(10 \%, \mathrm{v} / \mathrm{v})$. Unless otherwise stated, results were read after 7 days. Further changes were not observable after 21 days.

Yeast peptone agar plates. Colonies circular, c. $0.2 \mathrm{~mm}$. diam., translucent with entire margins. In some cultures growth became confluent and spread to a limited extent as a thin film. Growth was poor but sporulation often good (Pl. 1, fig. 2).

Yeast peptone cellobiose $(0.1 \%, w / v)$ agar plates. Incubation for 4 days. Colonies circular, 0.1-1.0 mm. diam., consisting of a central convex portion, finely granular with entire margins, surrounded by a thin, flat, transparent zone with irregular margins (Pl. 1, fig. 3). The growth often spread as a thin film.

Nutrient agar plates. Growth poor. Colonies flat, thin, transparent, irregular in size and shape, with dendroid margins.

Nutrient glucose $(0 \cdot 1 \%$, w/v) agar plates. Colonies with radiating projections which showed anti-clockwise curving (Pl. 1, fig. 4). These projections consisted of two elements, a smooth convex zone with a flat irregular fringe (Pl. 1, figs. 5-7).

Peptone water (Oxoid). Slight turbidity.

Cooked meat medium (Oxoid). Slight growth. Supernatant fluid faintly turbid. Meat particles became faintly pink compared with uninoculated controls. No change in odour.

No growth was detected on blood agar, MacConkey agar, potato, Loeffler's serum, or in nutrient gelatine (stab) and litmus milk. Growth was inhibited completely in yeast peptone cellobiose agar containing crystal violet (10 p.p.m.), brilliant green (10 p.p.m.), or bile salts (0.5\%, w/v).

Fermentation of carbohydrates. Tests were made in plugged tubes containing $10 \mathrm{ml}$. yeast peptone solution. Substrates were added at $0.2 \%(\mathrm{w} / \mathrm{v})$ and the media sterilized at $10 \mathrm{lb}$./sq.in. for $10 \mathrm{~min}$. Results were read after 5 days (Table 1). All cultures gave negative indole, vanillin-violet (Spray, 1936) and Voges-Proskauer tests.

Liquid cellulose media in sealed 1 oz. bottles. Attack on the cellulose was slow and several stages in the process were discerned. Typically, very little happened during the first week of incubation, but at the end of this period the flocculi of cellulose were larger than before inoculation. After 14 days, the cellulose became viscid and frequently aggregated into a single clot. Usually there was no apparent diminution in the amount of cellulose present in this 
time and the supernatant fluid remained clear. Digestion of the substrate then proceeded and sometimes became complete during the next 2 or 3 weeks. At some stage during active digestion bacteria were released from close contact with the cellulose and rendered the supernatant fluid turbid (Pl. 1, fig. 8). Turbidity which occurred a few days after inoculation was an almost certain indication of contamination. The presence of motile organisms at a late stage was demonstrated by removing a loop of viscid sediment from a 15-day culture and examining it in a special hanging-drop chamber through which a slow current of $\mathrm{O}_{2}$-free nitrogen $(25 \mathrm{ml}$./min.) was passed. No motile bacteria were found at first but after $5 \mathrm{~min}$. motile organisms began to migrate from the cellulose particles. Motility was not vigorous and most organisms remained inactive.

Table 1. Fermentation of carbohydrates $(0 \cdot 2 \%$, w/v, in yeast peptone broth)

Anaerobic. 5 days incubation.

$\begin{array}{lccccc} & \begin{array}{c}\text { pH uninoc. } \\ \text { control }\end{array} & \begin{array}{c}\text { Final } \\ \text { pH }\end{array} & \begin{array}{c}\text { Gas } \\ \text { fraction vol. } \\ \text { Durham tube }\end{array} & \text { Turbidity } & \begin{array}{c}\text { Methyl } \\ \text { red test }\end{array} \\ \text { *Control (no carbohydrate) } & \mathbf{7 \cdot 3} & \mathbf{6 \cdot 8} & - & - & - \\ \text { Arabinose } & \mathbf{7 \cdot 1} & \mathbf{5 \cdot 2} & \mathbf{0 \cdot 2 5} & +++ & + \\ \text { Xylose } & \mathbf{7 \cdot 1} & \mathbf{5 \cdot 2} & \mathbf{0 \cdot 5} & +++ & + \\ \text { Fructose } & \mathbf{7 \cdot 3} & \mathbf{5 \cdot 2} & \mathbf{0 \cdot 2 5} & +++ & + \\ \text { Galactose } & \mathbf{7 \cdot 2} & \mathbf{6 \cdot 6} & \text { Trace } & + & - \\ \text { tGlucose } & \mathbf{7 \cdot 2} & \mathbf{6 \cdot 2} & \mathbf{0 \cdot 1} & ++ & - \\ \text { Mannose } & \mathbf{7 \cdot 2} & \mathbf{5 \cdot 2} & \mathbf{0 \cdot 2} & +++ & + \\ \text { Cellobiose } & \mathbf{7 \cdot 2} & \mathbf{5 \cdot 2} & \mathbf{0 \cdot 5} & ++++ & + \\ \text { Lactose } & \mathbf{7 \cdot 3} & \mathbf{6 \cdot 1} & \mathbf{0 \cdot 1 5} & +++ & - \\ \text { Maltose } & \mathbf{7 \cdot 3} & \mathbf{5 \cdot 2} & \mathbf{0 \cdot 2 5} & +++ & + \\ \text { Sucrose } & \mathbf{7 \cdot 3} & \mathbf{6 \cdot 8} & - & - & - \\ \text { Melezitose } & \mathbf{7 \cdot 3} & \mathbf{6 \cdot 8} & - & \text { Trace } & - \\ \text { Raffinose } & \mathbf{7 \cdot 2} & \mathbf{6 \cdot 8} & - & \text { Trace } & - \\ \text { Dextrin } & \mathbf{7 \cdot 2} & \mathbf{6 \cdot 2} & \mathbf{0 \cdot 1} & ++ & - \\ \text { Inulin } & \mathbf{7 \cdot 3} & \mathbf{6 \cdot 8} & - & - & - \\ \text { Starch } & \mathbf{7 \cdot 3} & \mathbf{6 \cdot 8} & - & \text { Trace } & - \\ \text { Glycerol } & \mathbf{7 \cdot 2} & \mathbf{6 \cdot 8} & - & - & - \\ \text { Mannitol } & \mathbf{7 \cdot 3} & \mathbf{6 \cdot 8} & - & \text { Trace } & - \\ \text { Salicin } & \mathbf{7 \cdot 2} & \mathbf{6 \cdot 8} & - & \text { Trace } & -\end{array}$

* Presumably very slight growth in no-carbohydrate control and other cultures where only a small pH change occurred.

t In a parallel test lasting 15 days glucose cultures were the most acid ( $\mathrm{pH} \mathrm{4.8).}$

Turbidity: $-=$ clear medium; $+=$ slightly turbid; $++++=$ very turbid.

The times when these changes occurred in the cultures and when digestion was complete varied considerably; the reasons for these variations are unknown. Cellulose in these liquid cultures was rarely digested evenly (Pl. 1, fig. 9), although microscopic examination of the viscid mass revealed vast numbers of bacteria in all parts of it. Pits and closed cavities were often seen in the cellulose deposit; sometimes only one was present but usually they were numerous. Channelling of the cellulose by gas bubbles was usual.

Growth in deep agar culture. In $10 \mathrm{ml}$. portions of nutrient glucose agar $(0 \cdot 25 \%, w / v$, glucose) inoculated while molten, small buff opaque lenticular colonies usually grew during the first 7 days, but their appearance was 
invariably followed by the rapid development of spreading growth throughout the medium and abundant gas formation. Occasionally only the spreading gas-forming growth occurred. Experiments in which tubes of nutrient glucose agar and yeast peptone cellobiose agar were inoculated with organisms taken from both types of growth showed that there was no constant relationship between the type of inoculum used and the kind of culture resulting from it.

A dilution experiment was then made to determine whether a contaminant was still present or whether the isolate grew in two colonial forms. Two media were used : yeast peptone cellobiose agar, and this same medium enriched with filtrate from a grown liquid culture. This second medium was chosen because it had been observed that lenticular colonies usually developed before the spreading gas-forming growth and there was therefore a possibility that the appearance of the latter would be stimulated by the accumulation of metabolic products. This enriched medium was prepared as follows. A $50 \mathrm{ml}$. liquid culture in yeast peptone cellobiose medium was incubated anaerobically for 3 days and centrifuged. The centrifugate was adjusted to $\mathrm{pH} \mathbf{7 \cdot 0 - 7 \cdot 2}$, sterilized by passage through a sintered-glass filter and samples of $2.5 \mathrm{ml}$. added to $\mathbf{7 . 5} \mathrm{ml}$. portions of molten yeast peptone cellobiose medium containing $2 \%$, $\mathrm{w} / \mathrm{v}$, of agar. The final agar concentration was therefore $1.5 \%$, w/v. A few drops of turbid suspension were removed from a deep agar culture of the isolate and diluted with $2 \mathrm{ml}$. saline. From this original suspension dilutions of $1 / 10,1 / 50,1 / 100,1 / 500$ and 1/1000 were prepared. Duplicate tubes of normal and of enriched medium were inoculated, while molten, with each dilution (one loop to each tube). The results yielded no evidence for the presence of a contaminating organism. In all but the lowest dilutions, lenticular colonies developed first, as usually found previously, but any culture in which such colonies appeared also developed the spreading growth when incubation was continued long enough. After 20 days, observations were made on the single colony in the only $1 / 1000$ dilution tube to show growth. This was in most respects a normal opaque colony except that it was connected by a narrow projection to a split in the agar and this split was becoming heavily invaded by the spreading bacteria. A repeat experiment which yielded similar results to those described above also provided other good examples of this phenomenon. The most reasonable interpretation of it would seem to be that the organisms in one part of a discrete colony sometimes became motile and migrated from it, proliferating vigorously in existing splits or irregularities in the agar or at the glass agar interface. Thus all the evidence pointed to the presence of only one species which could form either discrete dense colonies which produced little or no gas, or which could become motile, highly invasive of the medium and forming gas abundantly. Neither form was sufficiently stable to isolate from the other, but spreading growth was partly suppressed by growing the isolate in yeast peptone cellobiose agar containing lithium chloride. This salt retarded both types of growth (Table 2), but at concentrations between 0.4 and $0.6 \%(\mathrm{w} / \mathrm{v})$ discrete colonies appeared before spreading growth; only discrete colonies grew at $0.7 \%(\mathrm{w} / \mathrm{v})$ and growth was inhibited completely at higher concentrations. 
Carbonate requirement. Liquid cellulose medium was modified by the addition of $1 \mathrm{ml}$. $\mathrm{N}-\mathrm{Na}_{2} \mathrm{CO}_{3} / 100 \mathrm{ml}$. medium; this concentration of carbonate had almost no effect on the $\mathrm{pH}$ value. Six replicate cultures (sealed $1 \mathrm{oz}$. bottles) were prepared and six control cultures set up with the same medium less carbonate. Cellulose was decomposed just as completely and rapidly whether carbonate had been added or not. Therefore, either carbonate was not required for the initiation of growth, or trace quantities which might be present in other constituents of the medium sufficed. Certainly the threshold requirement for carbonate, if any, must be low.

Table 2. The effect of lithium chloride on growth of the cellulolytic isolate in yeast peptone cellobiose agar

\begin{tabular}{|c|c|c|c|c|c|c|c|c|c|c|c|c|c|c|c|}
\hline \multirow{3}{*}{$\begin{array}{c}\text { Time } \\
\text { of } \\
\text { incu- } \\
\text { bation } \\
\text { (days) } \\
4\end{array}$} & \multicolumn{15}{|c|}{$\begin{array}{l}\text { Duplicate cultures prepared. } \\
\text { LiCl conc. }(\%, w / v) \text { in medium }\end{array}$} \\
\hline & \multicolumn{2}{|c|}{ 0 } & \multicolumn{2}{|c|}{0.2} & \multicolumn{2}{|c|}{$0 \cdot 3$} & \multicolumn{2}{|c|}{0.4} & \multicolumn{2}{|c|}{0.5} & \multicolumn{2}{|c|}{$0 \cdot 6$} & \multicolumn{2}{|c|}{0.7} & $\begin{array}{l}0 \cdot 8 \\
0.9\end{array}$ \\
\hline & $\begin{array}{l}\mathbf{D} \\
\mathbf{S}\end{array}$ & $\begin{array}{l}\mathbf{D} \\
\mathbf{S}\end{array}$ & - & - & - & - & - & - & - & - & - & - & - & - & - \\
\hline 5 & $\begin{array}{l}\mathbf{D} \\
\mathbf{S}\end{array}$ & $\begin{array}{l}\mathbf{D} \\
\mathbf{S}\end{array}$ & $\begin{array}{l}\mathbf{D} \\
\mathbf{S}\end{array}$ & $\begin{array}{l}\text { D } \\
\text { S }\end{array}$ & $\begin{array}{l}\mathbf{D} \\
\mathbf{S}\end{array}$ & $\begin{array}{l}\mathbf{D} \\
\mathbf{S}\end{array}$ & D & D & D & - & - & - & - & - & - \\
\hline 7 & $\begin{array}{l}\mathbf{D} \\
\mathbf{S}\end{array}$ & $\begin{array}{l}\mathbf{D} \\
\mathbf{S}\end{array}$ & $\begin{array}{l}\mathbf{D} \\
\mathbf{S}\end{array}$ & $\begin{array}{l}\mathbf{D} \\
\mathbf{S}\end{array}$ & $\begin{array}{l}\mathbf{D} \\
\mathbf{S}\end{array}$ & $\begin{array}{l}\mathbf{D} \\
\mathbf{S}\end{array}$ & $\begin{array}{l}\mathbf{D} \\
\mathbf{S}\end{array}$ & $\begin{array}{l}\mathbf{D} \\
\mathbf{S}\end{array}$ & D & $\mathbf{D}$ & - & D & - & - & - \\
\hline 9 & $\begin{array}{l}\mathbf{D} \\
\mathbf{S}\end{array}$ & $\begin{array}{l}\mathbf{D} \\
\mathbf{S}\end{array}$ & $\begin{array}{l}\mathbf{D} \\
\mathbf{S}\end{array}$ & $\begin{array}{l}\mathbf{D} \\
\mathbf{S}\end{array}$ & $\begin{array}{l}\mathbf{D} \\
\mathbf{S}\end{array}$ & $\begin{array}{l}\mathbf{D} \\
\mathbf{S}\end{array}$ & $\begin{array}{l}\mathbf{D} \\
\mathbf{S}\end{array}$ & $\begin{array}{l}\mathbf{D} \\
\mathbf{S}\end{array}$ & $\begin{array}{l}\mathbf{D} \\
\mathbf{S}\end{array}$ & $\mathbf{D}$ & - & $\mathbf{D}$ & - & - & - \\
\hline 12 & $\begin{array}{l}\mathbf{D} \\
\mathbf{S}\end{array}$ & $\begin{array}{l}\mathbf{D} \\
\mathbf{S}\end{array}$ & $\begin{array}{l}\mathbf{D} \\
\mathbf{S}\end{array}$ & $\begin{array}{l}\mathbf{D} \\
\mathbf{S}\end{array}$ & $\begin{array}{l}\mathbf{D} \\
\mathbf{S}\end{array}$ & $\begin{array}{l}\mathbf{D} \\
\mathbf{S}\end{array}$ & $\begin{array}{l}\mathbf{D} \\
\mathbf{S}\end{array}$ & $\begin{array}{l}\mathbf{D} \\
\mathbf{S}\end{array}$ & $\begin{array}{l}\mathbf{D} \\
\mathbf{S}\end{array}$ & $\mathbf{D}$ & - & $\begin{array}{l}\mathbf{D} \\
\mathbf{S}\end{array}$ & - & - & - \\
\hline 26 & $\begin{array}{l}\mathbf{D} \\
\mathbf{S}\end{array}$ & $\begin{array}{l}\mathbf{D} \\
\mathbf{S}\end{array}$ & $\begin{array}{l}\mathbf{D} \\
\mathbf{S}\end{array}$ & $\begin{array}{l}\mathbf{D} \\
\mathbf{S}\end{array}$ & $\begin{array}{l}\mathbf{D} \\
\mathbf{S}\end{array}$ & $\begin{array}{l}\mathbf{D} \\
\mathbf{S}\end{array}$ & $\begin{array}{l}\mathbf{D} \\
\mathbf{S}\end{array}$ & $\begin{array}{l}\mathbf{D} \\
\mathbf{S}\end{array}$ & $\begin{array}{l}\mathbf{D} \\
\mathbf{S}\end{array}$ & $\begin{array}{c}\mathbf{D} \\
\mathbf{S}\end{array}$ & $\begin{array}{l}\mathbf{D} \\
\mathbf{S}\end{array}$ & $\begin{array}{l}\mathbf{D} \\
\mathbf{S}\end{array}$ & D & $\mathbf{D}$ & - \\
\hline
\end{tabular}

Effect of contaminating organisms. Three unidentified strains of contaminating bacteria (all spore-bearing anaerobes) isolated from impure cellulose cultures were tested singly and together in liquid cellulose medium. Cultures of a duplicate set also received inocula of the cellulolytic isolate. Cellulose was digested only in those cultures which contained the isolate, and the rate of decomposition was not affected by the presence of the contaminants. The rapid digestion observed during the early stages of this work when definitely impure cultures were being used may have been due to synergistic action of some contaminants which soon died out during the purification procedures.

\section{Qualitative analysis of fermentation products}

Liquid cellulose medium ( $400 \mathrm{ml}$.) was boiled and cooled to room temperature with $\mathrm{O}_{2}$-free nitrogen passing the whole time. The medium was then added to a $20 \mathrm{oz}$. Winchester-type screw-capped bottle which had been flushed with nitrogen; $0 \cdot 2 \mathrm{~g}$. cysteine hydrochloride was then added and the cap tightened. 


\section{Anaerobic cellulose-decomposing bacteria}

After sterilization at $15 \mathrm{lb}$./sq.in. for $15 \mathrm{~min}$., the vessel was inoculated with the isolate, flushed with nitrogen and capped.

Acidic substances. After 42 days the contents of one $20 \mathrm{oz}$. bottle, from which most of the cellulose had disappeared, were filtered through no. 3 paper. The filtrate ( $\mathrm{pH} \mathrm{5.4)}$ ) was adjusted to $\mathrm{pH} 1.8$ with conc. $\mathrm{H}_{2} \mathrm{SO}_{4}$ and then extracted with ether in a liquid-liquid extractor for $40 \mathrm{hr}$. Twenty ml. of dilute $\mathrm{NaOH}$ were present with the $250 \mathrm{ml}$. ether in the solvent reservoir to neutralize the acids extracted. After extraction, the ether was removed by distillation and the aqueous residue saturated with $\mathrm{MgSO}_{4} .7 \mathrm{H}_{2} \mathrm{O}$ and brought to $\mathrm{pH} 1.9$ with conc. $\mathrm{H}_{2} \mathrm{SO}_{4}$. Five ml. of this extract (A) were steam-distilled and the volatile acids in $100 \mathrm{ml}$. distillate further concentrated by ether extraction and subsequent removal of the ether by distillation. The aqueous residue (extract $B$ ) was dried in a vacuum desiccator, taken up in $1 \mathrm{ml}$. water, neutralized with $\mathrm{NH}_{4} \mathrm{OH}$ and chromatographed (Reid \& Lederer, 1951). The position of the single spot formed indicated that the unknown consisted of formate or acetate or a mixture of both. The presence of both formic and acetic acids in the steam-distillate of extract $A$ was later confirmed by the method of Elsden (1946). Malic acid was also identified chromatographically in the residue from extract $\mathbf{A}$ after steam-distillation.

Sugars. A volume of culture filtrate $(200 \mathrm{ml}$.) was adjusted to $\mathrm{pH} 7.0$ and distilled under reduced pressure. The residue $(6.5 \mathrm{ml}$.) was treated with $100 \mathrm{ml}$. ethanol, filtered, evaporated to dryness under reduced pressure and dissolved in $5 \mathrm{ml}$. distilled water. This concentrate and the crude filtrate were both chromatographed on Whatman no. 4 paper with $n$-butanol/acetic acid/water $(4: 1: 5)$ as solvent system. A single spot was formed by the concentrate and by the filtrate; the position corresponded closely with that of glucose. There was no evidence for the presence of cellobiose in other than trace quantities. A repeat experiment using Whatman no. 1 paper with ethyl acetate/pyridine/water $(2: 1: 2)$ as solvent system gave similar results.

Gases. Samples of gas were withdrawn from an unopened $20 \mathrm{oz}$. culture bottle by means of a hypodermic needle passed through the rubber cap liner and connected directly with the gas analysis apparatus. The gas contained $19.9 \%$ carbon dioxide and $61 \cdot 8 \%$ hydrogen, the remainder being nitrogen. No hydrocarbon was present.

\section{DISCUSSION}

Growth of the isolate on cellulose in liquid and solid media is characterized by a long lag phase. This appears to be determined by the nature of the initial attack on the cellulose fibres because in media containing soluble substrates the lag phase is short and subsequent growth rapid. The possibility that slow initial growth on cellulose agar medium results from failure of the bacteria to make contact with cellulose particles is unlikely because similar slow growth also occurs in agar media in which the cellulose is effectively dispersed by carboxymethylcellulose. Digestion of cellulose, once begun, proceeds slowly when a pure culture is used and is often incomplete. The rate and completeness of this digestion may well be determined by accumulation of fermentation 
products inimical to continued growth of the organisms (Hungate, 1950). In nature, such accumulation would not be expected to occur because the products would in turn serve as substrates for other species of micro-organisms. Rapid fermentation noted with some early impure cultures might have been attributable to this cause.

Evidence is presented in support of the view that the isolate can exist in two growth forms. For example, surface colonies on yeast peptone cellobiose agar were usually composed of two distinct zones: a convex central portion and a flat thin irregular margin. The proportions of these two structural elements varied widely even between colonies on the same agar plate. Examples of variability in colony form are also to be found among some other species of Clostridia. For instance, Clostridium innominatum Prévot produces two kinds of colony on glucose agar: circular and entire, and diffuse and spreading. With some species this variability is held to be related to the presence of moisture on the agar surface. Thus, colonies of $C$. laniganii McClung \& McCoy on a glucose yeast agar are differentiated into convex central zones and effuse margins. The relative sizes of these zones vary with the strain. These colonies have a marked tendency to spread out into amoeboid projections on even slightly moist media (Lanigan, 1951).

The presence of a free water film on the surface of agar media may be partly responsible for the tendency of the cellulolytic isolate to spread, though the fact that spreading occurred easily on yeast peptone cellobiose medium containing $6 \%$ agar (Miles \& Hayward, 1943) suggested that it was not an important determining factor.

In deep agar, the isolate formed small discrete lenticular colonies or spread rapidly throughout the medium. Abundant gas was formed only by the spreading growth. Neither of these growth forms were stable and the behaviour of any particular culture could not be predicted. Barker \& Taha (1942) have reported two types of colony, fluffy spherical, and compact lenticular, of Clostridium kluyveri when grown in deep agar culture but they do not comment on the stability of these forms. Indeed, in all the literature on other species cited so far there is no suggestion of that extreme instability of the colony type characteristic of the cellulolytic isolate described in this paper.

Moreover, evidence for dissociation into two growth forms was given by studies in liquid cellulose media where moisture could not have been a controlling factor. In the early stages of growth the organism is non-motile and seems relatively inactive but later, the appearance of motile cells coincides with active digestion of the cellulose and more vigorous gas production. In some cultures onset of the second phase of digestion is delayed indefinitely and there is some evidence that both growth forms can exist side by side in the same culture (Pl. 1, fig. 9).

The isolate is distinguished from Clostridium spumarum Spray, and from C. leptinotarsae Sartory \& Meyer, by spore shape, failure to grow in peptone water or milk, by not producing indole, and by not forming butyric acid from cellulose. It differs from C. werneri Bergey et al. and C. dissolvens Bergey et al., by its ability to use a wide variety of carbohydrates other than cellulose; 
from $C$. cellulosolvens Cowles \& Rettger, by ability to ferment glucose, fructose, mannose, lactose and maltose; and from $C$. omelianskii Spray, by inability to liquefy gelatine, to grow in milk or to produce $\mathrm{H}_{2} \mathrm{~S}$ and by ability to ferment glucose, galactose, fructose, lactose and maltose.

In many respects the isolate closely resembles Clostridium cellobioparum Hungate, though the cells are somewhat larger and the rate of growth at $25^{\circ}$ is only a little slower than at $35^{\circ}$ or $37^{\circ}$. The greatest difference is the ability of the isolate to form glucose with little or no cellobiose from cellulose in liquid culture, whereas $C$. cellobioparum forms cellobiose and no glucose. However, the similarities between these two organisms are such that a close relationship between them seems highly probable. The isolate is, therefore, regarded as a strain of $\mathrm{C}$. cellobioparum. It is felt that more evidence, preferably serological, is required before a new specific name might be suggested.

I wish to thank Dr H. G. Thornton, For.Sec.R.S., and Dr P. S. Nutman for helpful advice during this investigation and Miss Mabel Dunkley for preparing the typescript. I am also indebted to the Hercules Powder Co. Inc., and to the Imperial Chemical Industries Ltd., for supplying me with generous samples of soluble cellulose derivatives.

\section{REFERENCES}

Barker, H. A. (1956). Bacterial Fermentations. New York: John Wiley and Sons Inc. London: Chapman and Hall Ltd.

Barker, H. A. \& TAha, S. M. (1942). Clostridium kluyveri, an organism concerned in the formation of caproic acid from ethyl alcohol. .J. Bact. 43, 347.

Clausen, P. (1931). Studien über anaerobe Zellulosebazillen unter besonderer Berücksichtigung der Züchtungstechnik. Zbl. Bakt. (2. Abt.), 84, 20.

Cowles, P. B. \& RETTGER, L. F. (1931). Isolation and study of an apparently widespread cellulose-fermenting anaerobe, $C$. cellulosolvens (n.sp.?). J. Bact. 21, 167.

Eisden, S. R. (1946). The application of the silica gel partition chromatogram to the estimation of volatile fatty acids. Biochem. J. 40, 252.

Fred, E. B. \& Waksman, S. A. (1928). Laboratory Manual of General Microbiology. New York: McGraw-Hill Book Co. Inc.

Hungate, R. E. (1944). Studies on cellulose fermentation. I. 'The culture and physiology of an anaerobic cellulose-digesting bacterium. J. Bact. 48, 499.

Hungate, R. E. (1947). Studies on cellulose fermentation. III. The culture and isolation of cellulose-decomposing bacteria from the rumen of cattle. J. Bact. $53,631$.

Hungate, R. E. (1950). The anaerobic mesophilic cellulolytic bacteria. Bact. Rev. $14,1$.

Khouvine, Y. (1923). Digestion de la cellulose par la flore intestinale de l'homme. B. cellulose dissolvens, n.sp. Ann. Inst. Pasteur, 37, 711.

Lanigan, G. W. (1951). The bacterial flora of Australian flax retting. Aust. J. Sci. Res. Ser. B, 4, 461.

Miles, A. A. \& Hayward, N. J. (1943). Inhibition of Proteus in cultures from wounds. Lancet, ii, 116.

Omelıanski, W. (1902). U'ber die Gärung der Cellulose. Zbl. Bakt.(2. Abt.Orig.), 8, 225.

Reid, R. L. \& Lederer, M. (1951). Separation and estimation of saturated $\mathrm{C}_{2}-\mathrm{C}_{7}$ fatty acids by paper partition chromatography. Biochem. J. 50, 60.

Siv, R. G. H. (1951). Microbial Decomposition of Cellulose. New York: Reinhold Publishing Corp.

Spray, R. S. (1936). Semisolid media for cultivation and identification of the sporulating anaerobes. J. Bact. 32, 135. 


\section{EXPLANATION OF PLATE 1}

Fig. 1. Cellulose agar culture derived from punctiform colony, in 3 oz. medical flat bottle. 40 days. The pure culture finally obtained originated from the haloed punctiform colony in the centre of the bottle. Cellulolytic area due to spreading surface film of bacteria below. Haloes of other punctiform colonies beginning to appear. $\times 1$.

Fig. 2. Sporulating organisms at edge of confluent thin spreading growth. Yeast peptone agar. 7 days. Stained with acetic acid aniline blue. $\times 983$.

Fig. 3. Surface colony on yeast peptone cellobiose $(0 \cdot 1 \%, w / v)$ agar. 5 days. Convex central zone and irregular flat fringe. Phase contrast. $\times 67$.

Fig. 4. Surface colonies on nutrient glucose agar. 7 days. Impression preparation. Anticlockwise deflexion of colony projections. Stained with acetic acid aniline blue. $\times 5 \cdot 4$.

Fig. 5. Surface colony on nutrient glucose agar. Radiating lobes with anti-clockwise deflexion. Raised convex growth with surrounding flat margin. Transmitted and oblique incident illumination. $\times 20$.

Fig. 6. Surface colony on nutrient glucose agar. 7 days. Tip of projecting lobe showing central convex zone and flat irregular margin. Phase contrast. $\times 67$.

Fig. 7. As 6. Raised convex areas embedded in flat irregular growth. Phase contrast. $\times 67$.

Fig. 8. Liquid cellulose medium $B$ cultures in $1 \mathrm{oz}$. screw-capped bottles. 45 days. Left to right: (a) uninoculated control; (b) cellulose viscid, supernatant fluid clear; (c) cellulose viscid and partially digested; supernatant fluid turbid; $(d)$ advanced stage of digestion ; supernatant fluid turbid. Slightly enlarged.

Fig. 9. Liquid cellulose culture (medium B). 45 days. Cellulose viscid but strongly digested only on side facing camera; supernatant fluid turbid. $\times 1.2$.

(Received 29 September 1959) 
Journal of General Microbiology, Vol. 22, No. 2
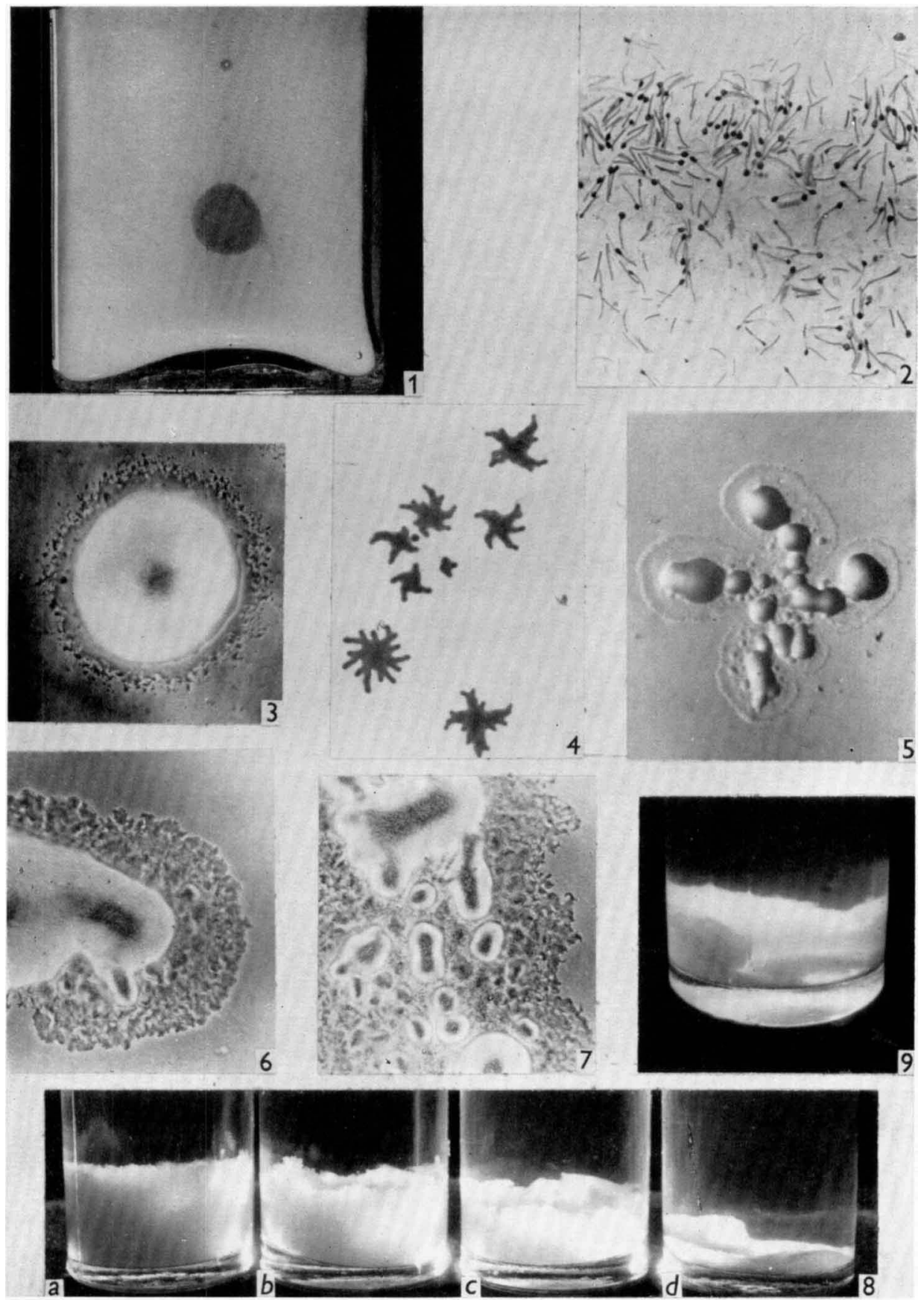

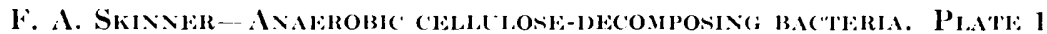
(Facing p. 5ist) 